\title{
Interrelationships of morphology, thermal and mechanical properties in uncrosslinked and dynamically crosslinked PP/EOC and PP/EPDM blends
}

\author{
R. R. Babu, N. K. Singha and K. Naskar* \\ Rubber Technology Centre, Indian Institute of Technology, Kharagpur-721302, West Bengal, India
}

Received 22 December 2009; accepted in revised form 28 January 2010

\begin{abstract}
Thermoplastic vulcanizates (TPVs) based on polypropylene (PP) with ethylene octene copolymer (EOC) and ethylene propylene diene rubber (EPDM) have been developed by coagent assisted dicumyl peroxide crosslinking system. The study was pursued to explore the influence of two dissimilar polyolefin polymers (EOC and EPDM) having different molecular architectures on the state and mode of dispersion of the blend components and their effects with special reference to morphological, thermal and mechanical characteristics. The effects of dynamic crosslinking of the PP/EOC and PP/EPDM have been compared by varying the concentration of crosslinking agent and ratio of blend components. The results suggested that the uncrosslinked and dynamically crosslinked blends of PP/EOC exhibit superior mechanical properties over PP/EPDM blends. From the hystersis experiments it was found that PP/EOC blends also perform better fatigue properties over PP/EPDM based blends. It was demonstrated that, the origin of the improved mechanical properties of EOC based blends is due to the combined effect of the unique molecular architecture with the presence of smaller crystals and better interfacial interaction of EOC phase with PP as supported by the results of thermal and fatigue analyses.
\end{abstract}

Keywords: polymer blends and alloys, polypropylene, ethylene octene copolymer, ethylene propylene diene rubber, thermoplastic vulcanizate

\section{Introduction}

Blending of polymers is often an important route for obtaining new and improved polymeric materials, which are difficult to obtain by direct polymerization process $[1,2]$. In addition to the family of synthesized thermoplastic elastomers (TPEs), advances in the rubber-plastic blends lead to the development of new avenues to prepare TPEs with tailor made properties by varying the blend ratio of the components. Thermoplastic vulcanizates (TPVs) are special class of TPEs prepared by dynamic vulcanization process which involves the crosslinking of rubber part while it is being mixed with the molten thermoplastic at high shear rate [3-5]. Amongst the various blends, polypropylene (PP)/ ethylene propylene diene rubber (EPDM) blends have gained tremendous importance due to commercial interest because of the structural compatibility. A large number of reports have been published on the PP/EPDM uncrosslinked and dynamically crosslinked blends [3-5]. Recently, new families of ethylene-alpha olefin copolymers have gained significant attention due to their unique molecular architecture with narrow molecular weight distribution, uniform co-monomer distribution and long chain branching along the polymer backbone [6]. Ethylene octene copolymer (EOC) in particular has been shown to provide better toughening characteristics to $\mathrm{PP}$, when compared with the conventionally used EPDM rubber [7, 8]. 
Presently, EOC is used for the impact modification of PP for various applications especially in the automotive sectors. Moreover, these materials are available in the form of pellets that help in easy handling, faster mixing and compounding. Nevertheless, reports on dynamically vulcanized PP/EOC TPVs are scanty. In case of TPVs, in addition to the constituent polymers, type of curing agent plays a major role in determining the final performance of the TPVs. Among several crosslinking systems used in the preparation of PP/EPDM TPVs, phenolic resin gained more commercial success due to its crosslinking and compatiblizing tendency [2]. However, in this particular PP/EOC blend system phenolic resin is ineffective, since the latter needs the presence of unsaturation to form a crosslinked network structure. Furthermore, use of phenolic resin in PP/EPDM blends causes black specks in the products which motivates the development of other crosslinking systems [9]. In that case, peroxides can be used which crosslink both saturated and unsaturated polymers without any reversion characteristics. However, the activity of peroxide depends on the type of polymer and presence of other ingredients in the system. It has been well established that PP exhibits $\beta$-chain scission (degradation) with the addition of peroxide [10]. Hence the use of peroxide alone is limited in the preparation of PP based TPVs. In general, to minimize the unwanted side reactions, coagent assisted peroxide crosslinking system is recommended. Naskar et al. [11, 12] studied the influence of different peroxides and multifunctional peroxide (having peroxide and coagent functionality in a single molecule) in the conventional PP/EPDM blends. Recently, Naskar et al. [13] have been involved in the development of a novel PP/EPDM TPVs by electron beam induced reactive processing. Special purpose TPVs based on silicone rubber [14] and maleated ethylene propylene rubber (m-EPM) [15] were also developed from the same lab. Lai et al. [16] investigated the fracture behavior and physicomechanical properties of peroxide cured PP/EOC TPVs. As a part of the extensive research work on the peroxide cured PP/EOC TPVs, our earlier report deals with the influence of different peroxides [17], different coagents [18] and different mixing sequences $[19,20]$ on the solid and melt state viscoelastic properties of PP/EOC TPVs.

The present study primarily aims to evaluate the performance of the coagent assisted peroxide cured PP/EOC TPVs as a potential alternative to the conventional PP/EPDM TPVs. In this work, the morphological evolution and its influence on the mechanical and thermal properties have been investigated for both PP/EOC and PP/EPDM uncrosslinked and dynamically crosslinked blends. Detailed comparisons were pursued on morphological, thermal and mechanical properties. Investigation had been made to correlate the observed results with the microstructural architecture of the constituent polymers.

\section{Experiemental}

\subsection{Materials}

Isotactic polypropylene (PP), ethylene-octene copolymers (EOC) and ethylene propylene diene rubber (EPDM) were used as blend components. Metallocene catalyzed ethylene octene copolymers (Exact ${ }^{\circledR}$ 5171) were employed in this study. The octene content of these Exact copolymers was

Table 1. Molecular characteristics of the polymers

\begin{tabular}{|c|c|c|c|}
\hline Polymer/properties & PP & EOC & EPDM \\
\hline Specific gravity & 0.90 & 0.87 & 0.86 \\
\hline MFI [g/10 min] & 3.0 at $230^{\circ} \mathrm{C} / 2.16 \mathrm{~kg}$ & 1.0 at $190^{\circ} \mathrm{C} / 2.16 \mathrm{~kg}$ & - \\
\hline $\mathrm{ML}(1+4)$ at $125^{\circ} \mathrm{C}$ & - & 25 & 55 \\
\hline$M_{n}[\mathrm{~g} / \mathrm{mol}]$ & 218967 & 277751 & 273082 \\
\hline$M_{w}[\mathrm{~g} / \mathrm{mol}]$ & 949319 & 494872 & 622876 \\
\hline $\mathrm{PDI}\left(M_{w} / M_{n}\right)$ & 4.33 & 1.78 & 2.28 \\
\hline Octene content $[\%]$ & - & 13 & - \\
\hline Ethylidene norbornene (ENB) content [\%] & - & - & 4.6 \\
\hline Propylene content [\%] & 99.9 & - & 25.4 \\
\hline Zero shear viscosity $[\mathrm{Pa} \cdot \mathrm{s}]^{*}$ & 1020 & 1980 & 4130 \\
\hline Grade & Koylene ADL (AS030N) & Exact 5171 & Keltan 5508 \\
\hline Supplier & IPCL, India & ExxonMobil Chemical, USA & DSM Elastomers, The Netherlands \\
\hline
\end{tabular}

MFI - Melt flow index; PDI - Polydispersity index; $M_{n}$ - number average molecular weight; $M_{w}-$ Weight average molecular weight *measured at a very low shear rate using Smart Rheo (Ceast, Italy) Capillary Rheometer at $180^{\circ} \mathrm{C}$ with $40: 1 \mathrm{~L} / \mathrm{D}$ capillary 
determined from Proton Nuclear Magnetic Resonance Spectroscopy $\left({ }^{1} \mathrm{H}-\mathrm{NMR}\right)$ measurement. The material and molecular characteristics of PP, EOC and EPDM are given in Table 1. The polymers taken for comparison are EOC and EPDM which were selected on the basis of number average molecular weight that lies relatively in the same range. Dicumyl peroxide (DCP) (Perkadox-BC40B-PD) having active peroxide content of $40 \%$; temperature at which half life time $\left(t_{1 / 2}\right)$ is 1 hour at $138^{\circ} \mathrm{C}$; specific gravity of $1.53 \mathrm{~g} / \mathrm{cm}^{3}$ at $23^{\circ} \mathrm{C}$ was obtained from Akzo Nobel Chemical Company, The Netherlands. N-N'-m-phenylene dimaleimide (MPDM) (SR 525; specific gravity, $1.44 \mathrm{~g} / \mathrm{cm}^{3}$ at $23^{\circ} \mathrm{C}$ ) was obtained from Sartomer Company, USA.

\subsection{Preparation of TPVs}

TPVs were prepared by melt mixing of PP with EOC/EPDM (rubbery material) in a Haake Rheomix 600s with a mixing chamber volume of $85 \mathrm{~cm}^{3}$ at a temperature of $180^{\circ} \mathrm{C}$. Batch sizes were about $60 \mathrm{~g}$. Total mixing time for each batch was 14 minutes. At first, PP was allowed to soften for 3 minutes and then rubbery material was added to the chamber and melt mixing was carried out for 5 minutes. Dynamic vulcanization was pursued by adding co-agent assisted peroxide for 2 minutes. Mixing was continued for another 4 minutes to complete the vulcanization. The compositions of TPVs employed for this study are shown in Table 2. For better understanding, blend ratios are designated as $\mathrm{X}, \mathrm{Y}$ and $\mathrm{Z}$ for 75,50 and $25 \%$ of $\mathrm{PP}$ respectively. TPVs prepared by different rubbery materials are designated as follows: $\mathrm{C}$ for EOC and $\mathrm{D}$ for EPDM. For example, YC corresponds to the composition of 50:50 PP/EOC uncrosslinked blends and ZD for 25:75 PP/EPDM uncrosslinked blend. Dynamically vulcanized blends are desig-

Table 2. TPV compositions in phr

\begin{tabular}{|c|c|c|c|}
\hline $\begin{array}{c}\text { Polymers/ } \\
\text { Designations }\end{array}$ & PP & EOC & EPDM \\
\hline XC & 75 & 25 & - \\
\hline YC & 50 & 50 & - \\
\hline ZC & 25 & 75 & - \\
\hline XD & 75 & - & 25 \\
\hline YD & 50 & - & 50 \\
\hline ZD & 25 & - & 75 \\
\hline
\end{tabular}

Prefix: D2 - Dynamically vulcanized blends with $2 \mathrm{phr}$ DCP D4 - Dynamically vulcanized blends with 4 phr DCP nated with prefixes D2 or D4 followed by corresponding blend ratio designation. The letter D2 or D4 corresponds to the type and concentration of peroxide (dicumyl peroxide of $2 \mathrm{phr}$ or $4 \mathrm{phr}$ ). For example, D2ZC corresponds to the composition containing $2 \mathrm{phr}$ (parts per hundred grams of rubber) of dicumyl peroxide in the 25:75 PP/EOC blend ratio. After mixing, the blends were removed from the chamber at hot condition and sheeted out on a two roll mill in a single pass. Sheets were then cut and pressed in a compression molding machine (Moore Press, Birmingham, UK) at $190^{\circ} \mathrm{C}$ for $4 \mathrm{~min}$ at $5 \mathrm{MPa}$ pressure. Aluminum foils were placed between the mold plates. The molded sheets were then cooled down to room temperature under the same pressure.

\subsection{Testing procedures}

Morphology - Morphology studies were carried out using a scanning electron microscope (SEM) (JEOL JSM 5800, Japan). Molded samples of PP/ EOC or PP/EPDM TPVs were cryofractured in liquid nitrogen to avoid any possibility of phase deformation during the fracture process. In case of uncrosslinked blends, the EOC or EPDM phase was preferentially extracted by treating with hot xylene at $50^{\circ} \mathrm{C}$ for $15 \mathrm{~min}$, whereas in dynamically vulcanized blends the PP phase was preferentially and partially extracted by etching with hot xylene at $100^{\circ} \mathrm{C}$ for $45 \mathrm{~min}$. The samples were then dried in a vacuum oven at $70^{\circ} \mathrm{C}$ for 5 hours to remove the traces of solvents present. Treated surfaces were then sputtered with gold before examination.

Differential Scanning Calorimetry (DSC) - DSC measurements were carried out in a TA instrument, USA (Model DSC Q100 V 8.1) to study the melting behavior. The samples of about $6 \mathrm{mg}$ sealed in aluminum pans were heated from -80 to $200^{\circ} \mathrm{C}$ at a scanning rate of $10^{\circ} \mathrm{C} / \mathrm{min}$ under nitrogen atmosphere. The degree of crystallinity of PP was determined from the heating curve by using standard formula which was discussed earlier by the authors $[17,18]$.

Mechanical Testing - The dumb-bell shaped specimens of the TPV used for testing were die cut from the compression molded sheet and the testing was done after 24 hours of maturation at room temperature. Tensile strength was measured according to ASTM D418-98A using a universal testing 
machine Hounsfield H10KS (UK) at a constant cross-head speed of $500 \mathrm{~mm} / \mathrm{min}$. Tension set was performed at room temperature with a stretching condition for 10 minutes at $100 \%$ elongation according to the ASTM D412-98 method.

Cyclic Tensile Testing - The tensile testing specimen was used to perform the hysteresis and fatigue life testing of the samples. The loading and unloading cross-head speed of $500 \mathrm{~mm} / \mathrm{min}$ was maintained. All the values were measured at the room temperature $\left(25^{\circ} \mathrm{C}\right)$ in air without any pretreatment. The hysteresis measurements were done in two modes i.e. constant strain amplitude and stepwise increase in strain amplitude.

Overall Crosslink Density (OCD) - Equilibrium solvent swelling measurements were carried out on the PP/EOC TPVs to determine the crosslink density of the EOC (v) in presence of PP $[11,17]$. The overall crosslink density was calculated using the modified Flory-Rehner equation [21]. From the degree of swelling, the overall crosslink density was calculated relative to the $(\mathrm{EOC}+\mathrm{PP})$ phases and expressed as $(\mathrm{v}+\mathrm{PP})$. The latter was done in order to avoid the need to correct for a part of the PP, being extracted as amorphous PP. A circular piece of $2 \mathrm{~mm}$ thickness was made to swell in cyclohexane for about 48 hours to achieve equilibrium swelling condition. Initial weight, swollen weight and de-swollen or dried weight were measured and substituted in the Equation (1):

$(v+P P)=-\frac{1}{V_{s}} \cdot \frac{\ln \left(1-V_{r}\right)+V_{r}+\chi\left(V_{r}\right)^{2}}{\left(V_{r}\right)^{1 / 3}-0.5 V_{r}}$

where $v$ - number of moles of effectively elastic chains per unit volume of EOC $[\mathrm{mol} / \mathrm{ml}]$ (crosslink density), ( $v+P P)$ - crosslink density of EOC phase in the presence of PP (overall crosslink density),
$V_{s}$ - molar volume of cyclohexane $\left[\mathrm{cm}^{3} / \mathrm{mol}\right], \chi-$ polymer swelling agent interaction parameter, which in this case is 0.306 [11] and $V_{r}$ - volume fraction of ethylene-octene copolymer in the swollen network, which can be expressed by Equation (2):

$$
V_{r}=\frac{1}{A_{r}+1}
$$

where $A_{r}$ is the ratio of the volume of absorbed cyclohexane to that of ethylene-octene copolymer after swelling.

\section{Results and discussion}

\subsection{Processing characteristics}

Mixing torque-time relationship (processing characteristics) of uncrosslinked and dynamically crosslinked blends were recorded from Haake Rheomix. The stabilized torque value is the characteristic feature of the viscous nature of the melt. It clearly indicates that the stabilized torque value increases with increase in rubber (EOC or EPDM) content as shown in Table 3. As mentioned previously (Table 1), EPDM has higher molecular weight and chain entanglement density relative to EOC. Therefore, EPDM macromolecules show higher resistance to the chain conformation and thereby show higher torque values than EOC based blends. In the dynamically vulcanized blends, the processing characteristic is more or less similar to that of corresponding uncrosslinked blends until the curative (peroxide with coagent) is added. When the curative is added, torque value increases, reaches maximum and then decreases before being stabilized. Typical torque-time relationship of 50/50 PP/EOC and PP/EPDM uncrosslinked and

Table 3. Mixing torque values of the uncrosslinked and dynamically crosslinked blends

\begin{tabular}{|c|c|c|c|c|c|}
\hline \multirow[b]{2}{*}{$\begin{array}{c}\text { Compound } \\
\text { name }\end{array}$} & \multicolumn{2}{|c|}{ PP/EOC } & \multirow[b]{2}{*}{$\begin{array}{c}\text { Compound } \\
\text { name }\end{array}$} & \multicolumn{2}{|c|}{ PP/EPDM } \\
\hline & $\begin{array}{l}\text { Maximum torque } \\
\text { value after adding } \\
\text { curative }[\mathrm{N} \cdot \mathrm{m}]\end{array}$ & $\begin{array}{l}\text { Torque value at the } \\
\text { end of the mixing } \\
\text { cycle }[\mathrm{N} \cdot \mathrm{m}]\end{array}$ & & $\begin{array}{l}\text { Maximum torque } \\
\text { value after adding } \\
\text { curative }[\mathrm{N} \cdot \mathrm{m}]\end{array}$ & $\begin{array}{l}\text { Torque value at the } \\
\text { end of the mixing } \\
\text { cycle }[\mathrm{N} \cdot \mathrm{m}]\end{array}$ \\
\hline $\mathrm{XC}$ & - & 3.5 & $\mathrm{XD}$ & - & 4.0 \\
\hline $\mathrm{YC}$ & - & 5.3 & YD & - & 6.8 \\
\hline $\mathrm{ZC}$ & - & 6.8 & ZD & - & 11.4 \\
\hline $\mathrm{D} 2 \mathrm{XC}$ & 7.6 & 2.5 & D2XD & 6.9 & 1.8 \\
\hline $\mathrm{D} 2 \mathrm{YC}$ & 14.0 & 7.4 & D2YD & 14.3 & 7.2 \\
\hline $\mathrm{D} 2 \mathrm{ZC}$ & 20.6 & 17.3 & D2ZD & 22.7 & 17.2 \\
\hline $\mathrm{D} 4 \mathrm{XC}$ & 7.4 & 1.6 & D4XD & 7.0 & 1.2 \\
\hline D4YC & 15.2 & 7.0 & D4YD & 15.5 & 6.8 \\
\hline D4ZC & 23.3 & 20.1 & D4ZD & 25.5 & 19.8 \\
\hline
\end{tabular}




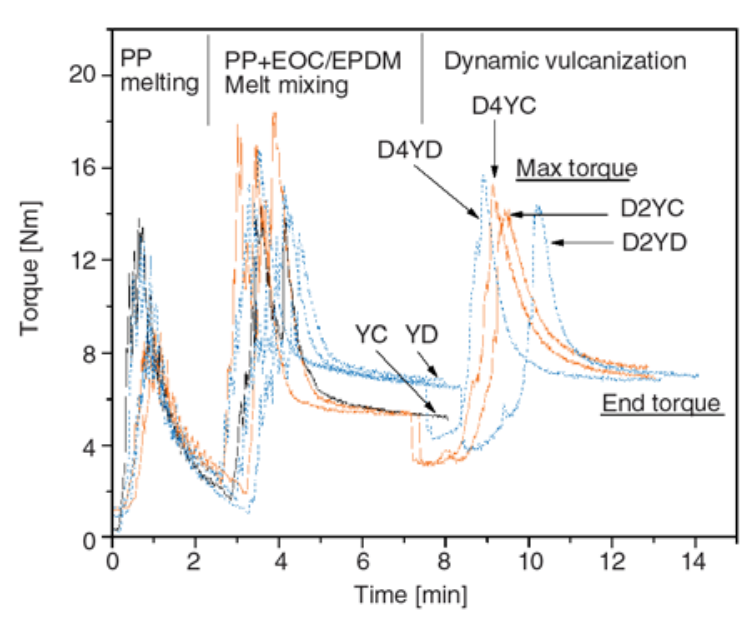

Figure1. Comparative mixing torque-time relationship of 50/50 PP/EOC and PP/EPDM uncrosslinked and dynamically crosslinked blends

dynamically crosslinked blends are shown in Figure 1 . The increase in torque is due to the crosslinking occurring in the EOC or EPDM phases. Decrease in torque value after reaching the maximum is expected due to the combined effect of the disintegration of crosslinked EOC or EPDM domains and also by the degradation in the PP phase through $\beta$-scission [22]. The maximum torque value after adding the curative and the torque value at the end of the mixing cycle for different compositions are given in the Table 3. Depending on the composition and polymer type, extent of degradation and crosslinking might be resolved. Samples with higher amount of PP (XC and XD) having $75 \%$ of PP, suffer severe degradation in PP phase during dynamic vulcanization. Therefore end torque (final torque) value decreases with the addition of curative with respect to uncrosslinked blends. Nevertheless, torque value increases initially after the addition of curative, which may be associated with the crosslinking that takes place in the EOC or EPDM phase. In case of $\mathrm{YC}$ and YD blends containing $50 \%$ of PP, there exists equal contribution to crosslinking in the rubbery phase and chain-scission in the PP phase. It is worth noting that the maximum torque increases and end torque decreases as a function of curative dosage. In ZC and ZD blends containing $25 \%$ of PP curative is mostly consumed by the rubbery phase and overrides the degradation in PP phase. This reflected to increase both the end torque and maximum torque values as a function of curative dosage (within the curative concentration limit). The above results suggest that the maximum torque value increases with increase in rubber content in both the systems (PP/EOC and PP/EPDM).

It is to be noted here that, EPDM based TPVs show lower end torque values than corresponding EOC based TPVs at identical rubber/plastic composition. EPDM is a random terpolymer of ethylene, propylene and diene units and with the addition of peroxide, propylene units undergo chain-scission and/or disproportionation as side reaction apart from the crosslinking in the ethylene units. Hence EPDM based TPVs suffer severe degradation than EOC based TPVs. Apparently, peroxide at the higher curative dosage $(4 \mathrm{phr})$ not only increases the extent of crosslinking in EOC or EPDM phase but also causes significant degradation in the PP phase.

\subsection{Morphology}

In general, phase morphology of the heterogeneous polymer blends are mainly determined by viscosity ratio, blend ratio and interfacial tension [23]. Several authors [24-27] surveyed the morphology and rheology of various kinds of polyolefin blends with special reference to the varying blend ratios. Figure 2 shows the SEM photomicrographs of 50/50 blend ratio of PP/EOC and PP/EPDM uncrosslinked and dynamically crosslinked blends. In uncrosslinked blends, rubbery phase EOC or EPDM was preferentially extracted and in dynamically crosslinked blends PP phase was preferentially extracted. Both the uncrosslinked compound (YC and YD) results in the formation of co-continuous phase morphology. Depending on the viscosity ratio, various levels of co-continuity exist in the blend compounds. It is clear from the Figures $2 \mathrm{a}$ and $2 b$ that the PP/EOC (YC) contributes to have higher percentage of co-continuity than PP/EPDM (YD) blend. Because of higher viscosity ratio in YD, EPDM prefers to exist in dispersed phase. However by dynamic vulcanization, a complete phase transition (inversion) occurs i.e. co-continuous morphology is changed into dispersed phase morphology. The less viscous PP encapsulates the more viscous crosslinked rubber particles to minimize the mixing energy $[22,23]$. At equal curative dosage of $2 \mathrm{phr}$ DCP and compositional volume, PP/EPDM TPV shows coarser crosslinked rubber particle size than PP/EOC TPV (Figures $2 c$ and $2 \mathrm{~d})$. By increasing the concentration of peroxide (4 phr) in order to increase the crosslink density of 

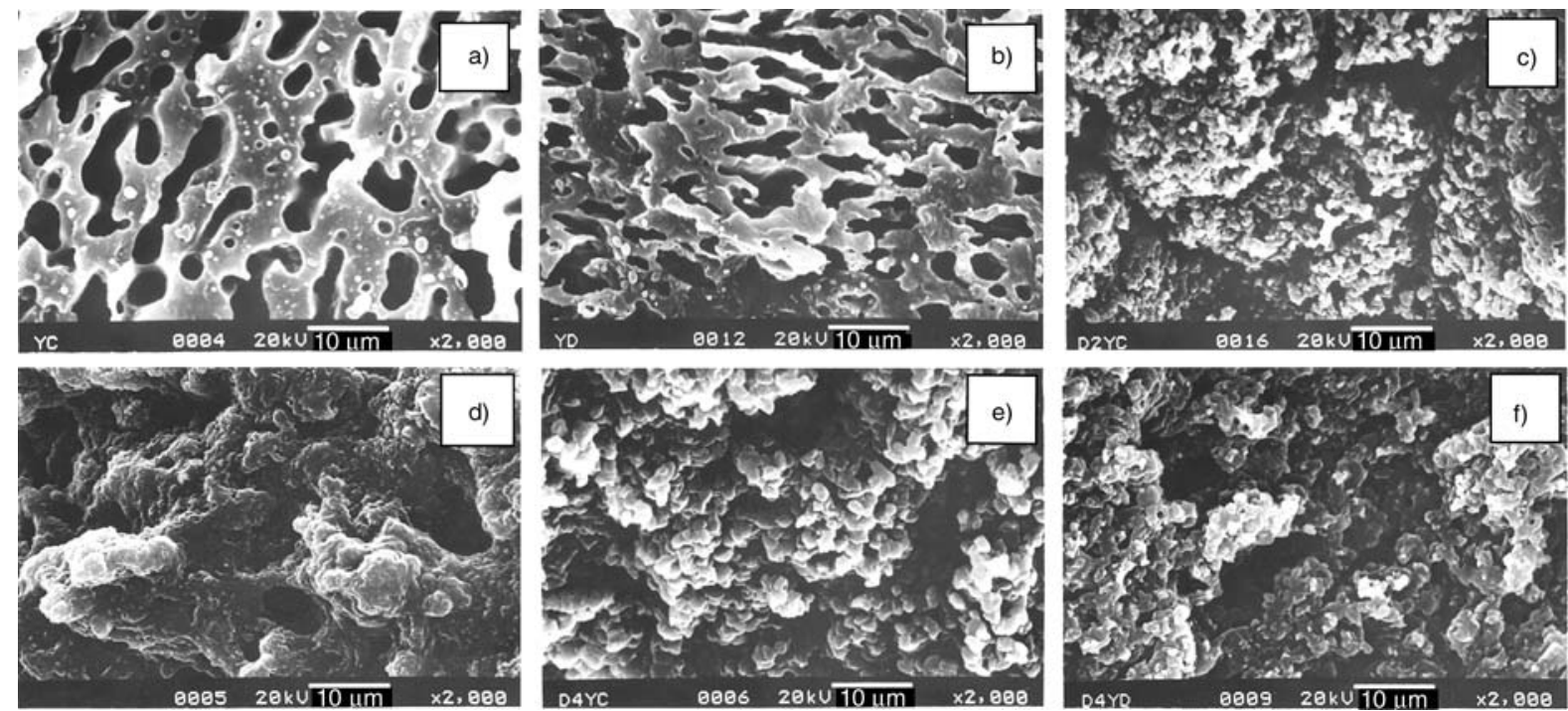

Figure 2. SEM photomicrographs of a) YC (50/50 PP/EOC uncrosslinked) b) YD (50/50 PP/EPDM uncrosslinked) c) D2YC (dynamically vulcanized; 2 phr) d) D2YD (dynamically vulcanized; 2 phr) e) D4YC (dynamically vulcanized; 4 phr) f) D4YD (dynamically vulcanized; 4 phr)

rubber phase, two opposite behaviors have been accounted in the particle size evolution for PP/EOC and PP/EPDM blend. Crosslinked rubber particles size increases in PP/EOC blends, whereas decreases in PP/EPDM blend as a function of peroxide concentration (Figures 2e and 2f). It is well known that, PP undergoes chain-scission with the addition of peroxide. In case of PP/EOC blends when the concentration of peroxide increases from 2 to $4 \mathrm{phr}$, extent of degradation in the PP phase dominates over crosslinking in the EOC phase. Therefore, it becomes too difficult for a relatively very low viscosity PP matrix (low molecular weight PP) to break-up the crosslinked EOC rubber. But in case of PP/EPDM blends, in addition to the PP-matrix chain-scission, the inherent PP segments in the EPDM also undergo chain-scission which cause to form low molecular weight compound. These low molecular weight compounds have higher tendency towards fine dispersion by lowering the viscosity ratio.

\subsection{Thermal properties}

DSC measurements were performed to characterize the crystallization and melting behavior of uncrosslinked and dynamically vulcanized blends. Figure 3 shows the DSC cooling and heating curves of 50/50 rubber/plastic blend ratio of uncrosslinked and dynamically vulcanized blends. Table 4 summarizes the relevant thermal parameters as obtained from the DSC scans. It can be seen from the Table 4, that neat PP exhibits a characteristic feature of semi-crystalline polymer with glass transition $\left(T_{g}\right)$, melting temperature $\left(T_{m}\right)$ and crystallization temperature $\left(T_{c}\right)$ at around 1,165 and $119^{\circ} \mathrm{C}$, respectively. Pristine EOC shows a strong $\beta$-transition (step in DSC heat capacity traces) due to its movement of octene branch points at $-50^{\circ} \mathrm{C}$. On contrary, EPDM shows a transition at $-45^{\circ} \mathrm{C}$ due to the relaxation of short chain branch points. But, PP does not show a significant change in $\beta$-transition in the DSC traces due to its semi-crystalline characteristics. Both EOC and EPDM show the occur-

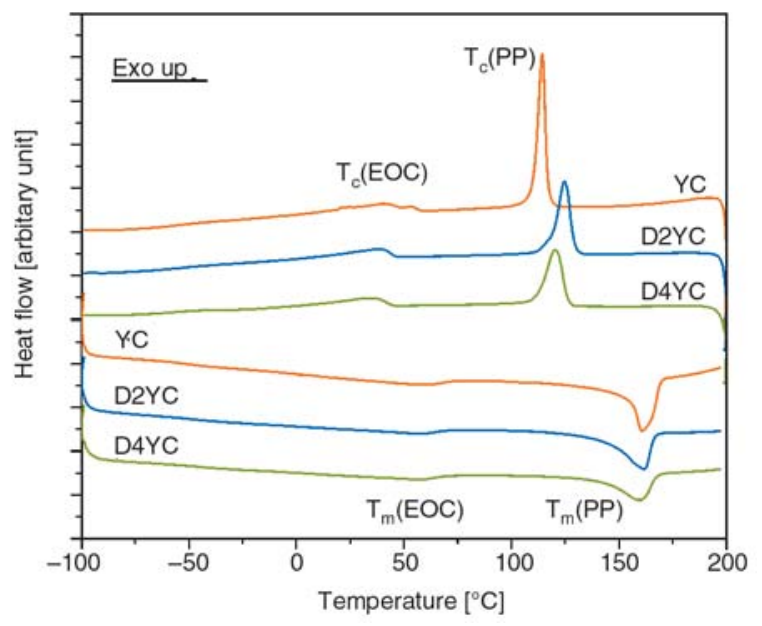

Figure 3. DSC curves of melting endotherm and crystallization exotherm of 50/50 rubber/plastic uncrosslinked and dynamically crosslinked blends. (second heating scan and cooling scan of the blends after subjecting them to same thermal history) 
Table 4. Crystallization and melting characteristics of uncrosslinked and dynamically crosslinked blends

\begin{tabular}{|c|c|c|c|c|c|c|c|c|c|c|}
\hline \multirow{2}{*}{$\begin{array}{c}\text { Compound } \\
\text { name }\end{array}$} & \multicolumn{9}{|c|}{$\mathbf{P P}$} & \multicolumn{5}{c|}{ EOC/EPDM } \\
\cline { 2 - 13 } & $\mathbf{T}_{\mathbf{g}}\left[{ }^{\circ} \mathbf{C}\right]$ & $\mathbf{T}_{\mathbf{m}}\left[{ }^{\circ} \mathbf{C}\right]$ & $\Delta \mathbf{H}_{\mathbf{f}}[\mathbf{J} / \mathbf{g}]$ & $\mathbf{X}_{\mathbf{c}}[\mathbf{\%}]$ & $\mathbf{T}_{\mathbf{c}}\left[{ }^{\circ} \mathbf{C}\right]$ & $\mathbf{T}_{\mathbf{g}}\left[{ }^{\circ} \mathbf{C}\right]$ & $\mathbf{T}_{\mathbf{m}}\left[{ }^{\circ} \mathbf{C}\right]$ & $\Delta \mathbf{H}_{\mathbf{f}}[\mathbf{J} / \mathbf{g}]$ & $\mathbf{X}_{\mathbf{c}}[\boldsymbol{\%}]$ & $\mathbf{T}_{\mathbf{c}}\left[{ }^{\circ} \mathbf{C}\right]$ \\
\hline PP & 1 & 165 & 99.32 & 47.52 & 119 & - & - & - & - & - \\
\hline EOC & - & - & - & - & - & -50 & 60 & 18.9 & 6.55 & 45 \\
\hline EPDM & - & - & - & - & - & -45 & 38 & 8.2 & 2.85 & 20 \\
\hline YC & 1 & 162 & 48.7 & 46.63 & 113 & -47 & 60 & 7.5 & 5.17 & 42 \\
\hline D2YC & 2 & 161 & 46.5 & 44.52 & 124 & -46 & 58 & 6.4 & 4.41 & 40 \\
\hline D4YC & 2 & 160 & 33.9 & 32.44 & 120 & -45 & 58 & 5.5 & 3.76 & 37 \\
\hline YD & 0 & 162 & 45.8 & 43.82 & 114 & -43 & 37 & 3.6 & 2.48 & 19 \\
\hline D2YD & 2 & 161 & 45.3 & 43.34 & 125 & -38 & 33 & 5.1 & 3.51 & 18 \\
\hline D4YD & 2 & 158 & 45.2 & 43.22 & 124 & -38 & 33 & 4.0 & 2.75 & 18 \\
\hline
\end{tabular}

$T_{g}$ - Glass transition temperature, $T_{m}$ - Peak melting temperature, $\Delta H_{f}$ - Heat of fusion value, $X_{c}$ - Percentage crystallinity calculated from heat of fusion data, $T_{c}-$ Crystallization temperature

rence of $T_{m}$ and $T_{c}$, suggesting the presence of crystalline phase. It is expected that, both EOC and EPDM seem to have long enough ethylene blocks, which are easy to crystallize in a usual manner. However, depending on its inherent molecular architecture $T_{c}$ of EOC and EPDM are 45 and $20^{\circ} \mathrm{C}$ respectively.

At 50/50 rubber/plastic blend ratio (YC and YD), $T_{m}, T_{c}$ and $X_{c}$ found to vary significantly for both $\mathrm{PP}$ as well as for rubbery component. The possible inter-diffusion and inter-molecular mixing reduces the size and perfectness of crystals and consequently inhibits the crystallization process on either component as also reported by Bielinski et al. [28]. The results, therefore, suggest that PP blended with EOC or EPDM needs higher undercooling to crystallize (i.e., rubbery components may depress the crystallization of PP) and correspondingly decrease the $T_{c}$. It is worth noting that the addition of rubbery component broadens the melting endotherms of PP phase, which is probably due to the changes in the distribution of crystal lamella thickness.

Upon dynamic vulcanization, significant changes in the thermal properties were observed in both PP and rubbery phases. Apparently, as the peroxide dosage increases from 0 to $4 \mathrm{phr}$ in PP/EOC blend, $T_{g}$ marginally increases, $T_{m}$ as well as $X_{c}$ decrease continuously in the EOC phase due to low degree of chain alignment resulting from predominant crosslinking. As for PP matrix phase, variation in the $T_{g}$ is marginal whereas $T_{m}$ and $X_{c}$ continuously decrease as the curative concentration increases. A similar trend is found for the PP/EPDM TPVs. It is very clear from the Table 4, the extent of decrease in $X_{c}$ of PP is more pronounced for PP/EOC TPVs as a function of curative concentration i.e., $X_{c}$ of PP decreased from 46.6 to $32.4 \%$ with addition of
4 phr of peroxide. Bulk crystallization temperatures of both the components were found to vary significantly by dynamic vulcanization. As for the rubbery phase, $T_{c(\mathrm{EOC})}$ was found to decrease continuously in PP/EOC TPVs. This may be associated with the prominent crosslinking reaction in the EOC phase which needs higher under-cooling to crystallize. Whereas in case of PP/EPDM TPVs, EPDM undergoes simultaneously crosslinking in the ethylene sequence and chain-scission in the propylene sequence. The combined effect of the above mentioned two competing reactions inconsistently affect the crystallization process of EPDM phase. As the peroxide dosage increases from 0 to $4 \mathrm{phr}$ (with in the given concentration limit), the $T_{c(\mathrm{PP})}$ was found to increase and then decrease for PP/EOC based TPVs. At 4 phr concentration of peroxide, chain scission in the PP phase dominates over the crosslinking effect in the EOC phase. Therefore, the lower molecular weight PP chains have less under-cooling effect to crystallize. But in case of PP/EPDM TPVs, $T_{c(\mathrm{PP})}$ initially increases and then gets stabilized, which is mainly due to the competition between the chain coupling reaction in the polyethylene segments and chain scission reaction in the polypropylene segments in the EPDM phase.

\subsection{Mechanical properties}

The effect of blend composition on the tensile properties of PP/EOC and PP/EPDM uncrosslinked and dynamically vulcanized blends are compared and shown in Table 5. Comparative stress-strain properties of the blend components are shown in Figures $4 \mathrm{a}$ and $4 \mathrm{~b}$. Neat PP shows very high tensile strength and poor elongation, a characteristic fea- 
Table 5. Comparative physical properties of uncrosslinked and dynamically crosslinked blends

\begin{tabular}{|c|c|c|c|c|c|}
\hline $\begin{array}{l}\text { Compound } \\
\text { name }\end{array}$ & $\begin{array}{c}\text { Tensile strength } \\
{[\mathrm{MPa}]}\end{array}$ & $\begin{array}{c}\text { Elongation at break } \\
{[\%]}\end{array}$ & $\begin{array}{c}100 \% \text { modulus } \\
{[\mathrm{MPa}]}\end{array}$ & $\begin{array}{c}\text { Tension set } \\
{[\%]}\end{array}$ & $\begin{array}{l}\text { Overall crosslink density } \\
(\mathrm{v}+\mathrm{PP}) \cdot \mathbf{1 0}^{-4}[\mathrm{~mol} / \mathrm{ml}]^{\mathrm{a}}\end{array}$ \\
\hline PP & $39.6 \pm 1.2$ & $16 \pm 3$ & - & - & - \\
\hline EOC & $14.4 \pm 0.8$ & $1265 \pm 24$ & $2.1 \pm 0.2$ & $4 \pm 0.2$ & 0.06 \\
\hline EPDM & $3.51 \pm 0.4$ & $1485 \pm 35$ & $0.6 \pm 0.1$ & $2.5 \pm 0.3$ & 0.19 \\
\hline $\mathrm{XC}$ & $22.9 \pm 2.1$ & $91 \pm 11$ & - & - & 40.05 \\
\hline $\mathrm{YC}$ & $13.2 \pm 2.3$ & $155 \pm 15$ & $12.9 \pm 0.5$ & $36 \pm 1.2$ & 8.17 \\
\hline $\mathrm{ZC}$ & $9.2 \pm 1.2$ & $795 \pm 21$ & $5.4 \pm 0.4$ & $14 \pm 0.6$ & 0.38 \\
\hline $\mathrm{D} 2 \mathrm{XC}$ & $20.1 \pm 2.4$ & $16 \pm 3$ & - & - & 36.10 \\
\hline D2YC & $15.4 \pm 1.5$ & $237 \pm 12$ & $14.0 \pm 0.3$ & $32 \pm 0.8$ & 10.12 \\
\hline $\mathrm{D} 2 \mathrm{ZC}$ & $11.5 \pm 1.1$ & $300 \pm 15$ & $6.8 \pm 0.2$ & $12 \pm 0.3$ & 2.58 \\
\hline D4XC & $18.3 \pm 2.4$ & $14 \pm 2$ & - & - & 32.21 \\
\hline D4YC & $14.5 \pm 1.2$ & $200 \pm 8$ & $13.8 \pm 0.3$ & $28 \pm 0.5$ & 10.32 \\
\hline D4ZC & $11.5 \pm 0.5$ & $295 \pm 12$ & $7.0 \pm 0.2$ & $10 \pm 0.2$ & 3.72 \\
\hline XD & $19.7 \pm 1.6$ & $105 \pm 10$ & - & - & 46.15 \\
\hline YD & $11.9 \pm 1.0$ & $117 \pm 14$ & $11.9 \pm 0.3$ & $28 \pm 0.6$ & 13.92 \\
\hline $\mathrm{ZD}$ & $4.5 \pm 0.4$ & $477 \pm 18$ & $3.1 \pm 0.1$ & $8 \pm 0.2$ & 2.91 \\
\hline D2XD & $19.5 \pm 2.5$ & $17 \pm 2$ & - & - & 39.21 \\
\hline D2YD & $12.5 \pm 1.3$ & $150 \pm 13$ & $12.7 \pm 0.2$ & $24 \pm 0.4$ & 16.84 \\
\hline D2ZD & $9.9 \pm 0.8$ & $269 \pm 15$ & $5.3 \pm 0.2$ & $6 \pm 0.3$ & 4.92 \\
\hline D4XD & $15.4 \pm 1.5$ & $93 \pm 9$ & - & - & 32.38 \\
\hline D4YD & $13.9 \pm 0.0$ & $160 \pm 16$ & $12.5 \pm 0.3$ & $22 \pm 0.5$ & 16.21 \\
\hline D4ZD & $09.3 \pm 0.0$ & $222 \pm 19$ & $5.7 \pm 0.2$ & $5 \pm 0.2$ & 5.94 \\
\hline
\end{tabular}

aStandard deviation of overall crosslink density value lies in between $0.1-0.15$

ture of a brittle material. On the other hand, EPDM being primarily an amorphous polymer having unreliable amount of crystals due to the crystallizing nature of long chain polyethylene segments shows a typical uncrosslinked elastomer like deformation. The stress-strain behavior of EOC is similar to that of uncrosslinked rubber; however stress gradually increases with increase in strain level. This may be due to the crystallizing tendency of polyethylene segments during stretching (Figure $4 \mathrm{a}$, inset). A significant difference was observed in the deformation characteristics of the blends with varying compositions (Figure 4a). Samples $\mathrm{XC}$ and $\mathrm{XD}$ show necking and yielding region. It may be associated with the distribution and dispersion of rubber particles in inter- and intraspherulitic region of PP matrix to reduce the notch sensitivity and brittle fracture [29]. The yield stress value and the peak broadening are observed when the rubber content increases from 25 to $50 \%$ (YC and $\mathrm{YD}$ ). In case of ZC and ZD, elongation at break increase and modulus and tensile strength increase as compared to YC and YD. The improved rubbery behavior can be explained in terms of morphologi-
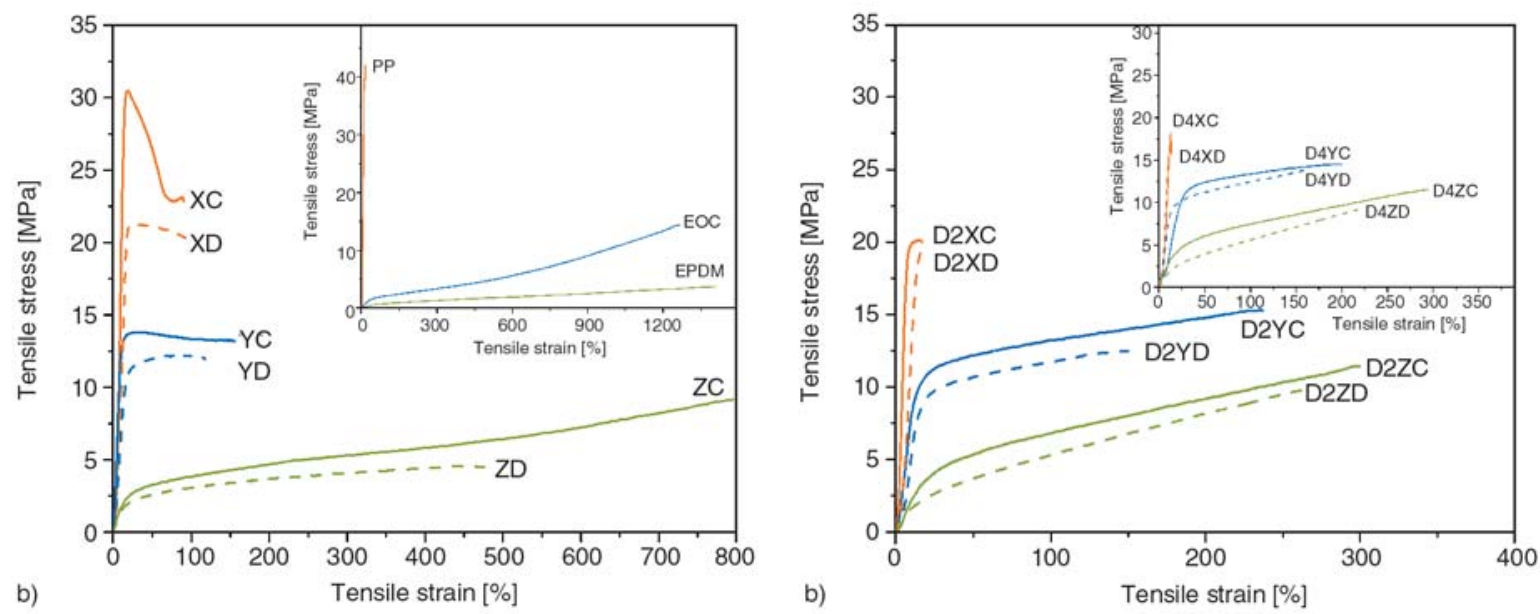

Figure 4. Stress-strain properties of (a) Uncrosslinked blends Inset: Pristine polymer (b) Dynamically vulcanized blends with $2 \mathrm{phr}$ concentrations of peroxide Inset: 4 phr peroxide 
cal evolution (phase transition of EOC or EPDM phase form co-continuous to continuous as the rubbery content increases from 50 to $75 \%$ as shown in the earlier sections).

The stress-strain curve of dynamically vulcanized blend with $2 \mathrm{phr}$ concentration of peroxide is shown in Figure $4 \mathrm{~b}$. For the compositions D2XC and $\mathrm{D} 2 \mathrm{XD}$, degradation in the PP phase results to show lower stress and strain values. In case of D2YC and D2YD, the nature of the curve significantly changes from plastic to elastic type with the disappearance of necking and yielding. Thereby, dynamically vulcanized samples exhibit improved tensile strength and elongation at break. The above change in the deformation mechanism is mainly associated with the evolution of phase morphology during dynamic vulcanization. Samples with higher rubber content (D2ZC and D2ZD) are more towards the elastic type with increased modulus and tensile strength and lower elongation at break. Furthermore, at higher peroxide dosage (4 phr), D4XC and D4XD show poor tensile and elongation at break values, which may be due to extensive degradation or chain-scission in the PP phase. In case of dynamically vulcanized 50/50 rubber/plastic content (D4YC and D4YD), marginal decrease in both tensile and elongation values suggest that, chain-scission in PP dominates over crosslinking in EOC or EPDM phase. Interestingly, not much difference is observed in the stress-strain values with increase in the curative dosage for samples with higher rubber content (ZC and ZD) (Figure 4b, inset graph).

When comparing the behavior of PP/EOC and PP/EPDM samples, in all the cases EOC based uncrosslinked and dynamically vulcanized blends exhibit better physical properties than PP/EPDM samples at identical composition. Since EPDM is an ethylene propylene diene random terpolymer, part of the propylene units undergoes chain-scission or degradation while using peroxide as curative. During dynamic vulcanization, as the concentration of curative increases from 0 to $4 \mathrm{phr}$, a higher level of degradation in the PP phase is coupled with the chain-scission in the PP segments in the EPDM polymer in PP/EPDM blends. Thereby PP/EPDM TPVs lose their mechanical strength despite containing the finest vulcanized rubber particles. Therefore, it is expected that dynamically vulcanized blends of PP/EPDM depict inferior physico-mechanical properties than PP/EOC TPVs.
From the DSC and SEM analyses, it was found that EOC containing small crystals have good affinity and finely dispersed particles in the PP matrix phase. On the other hand, EPDM itself contains small crystals but its crystallinity might be too low (due to high degree of chain entanglement density) to form an effective reinforcing characteristics. Although mechanical properties are found to be superior for PP/EOC blends, set properties are better for PP/EPDM blends.

Tension set and overall crosslink density (OCD) values show a good correlation for both PP/EOC and PP/EPDM uncrosslinked and dynamically crosslinked blends. As the concentration of peroxide increases form 0 to $4 \mathrm{phr}$ (in both the cases), samples with higher amount of PP suffer from chain scission and hence OCD value decreases continuously. However samples with 50 and $75 \%$ rubber content, OCD continuously increases. Particularly, the latter (75\% rubber content) shows significant increase in the OCD values with increase in peroxide concentration. These changes are associated with the chain coupling reactions in the rubbery phase. As a mater of fact, EPDM based blends show higher OCD values as compared to EOC based compounds. In case of EPDM based samples, the presence of natural physical entanglements at their characteristics network density would cause an increase in number of effective crosslink points per molecule (crosslink density) and correspondingly improve the set properties.

\subsection{Hysteresis}

In general, hysteresis measurements give information about the structural changes of the material under cyclic deformation. The samples are subjected to uniaxial tensile deformation at a constant speed of $500 \mathrm{~mm} / \mathrm{min}$ and the deformation was removed at the same speed. In general, due to the viscoelastic nature of the polymeric materials, the energy applied may not be balanced with energy released i.e., the stretching and recoiling curves form a closed loop called as hysteresis loop. The hysteresis loop of cyclic tensile curves of 50/50 rubber/plastic blend ratio of uncrosslinked and dynamically crosslinked blends at constant strain of $100 \%$ are shown in Figures 5a and 5b. During stretching, a 50:50 blend ratio of PP and rubbery components exhibit the stress-strain behavior, a 

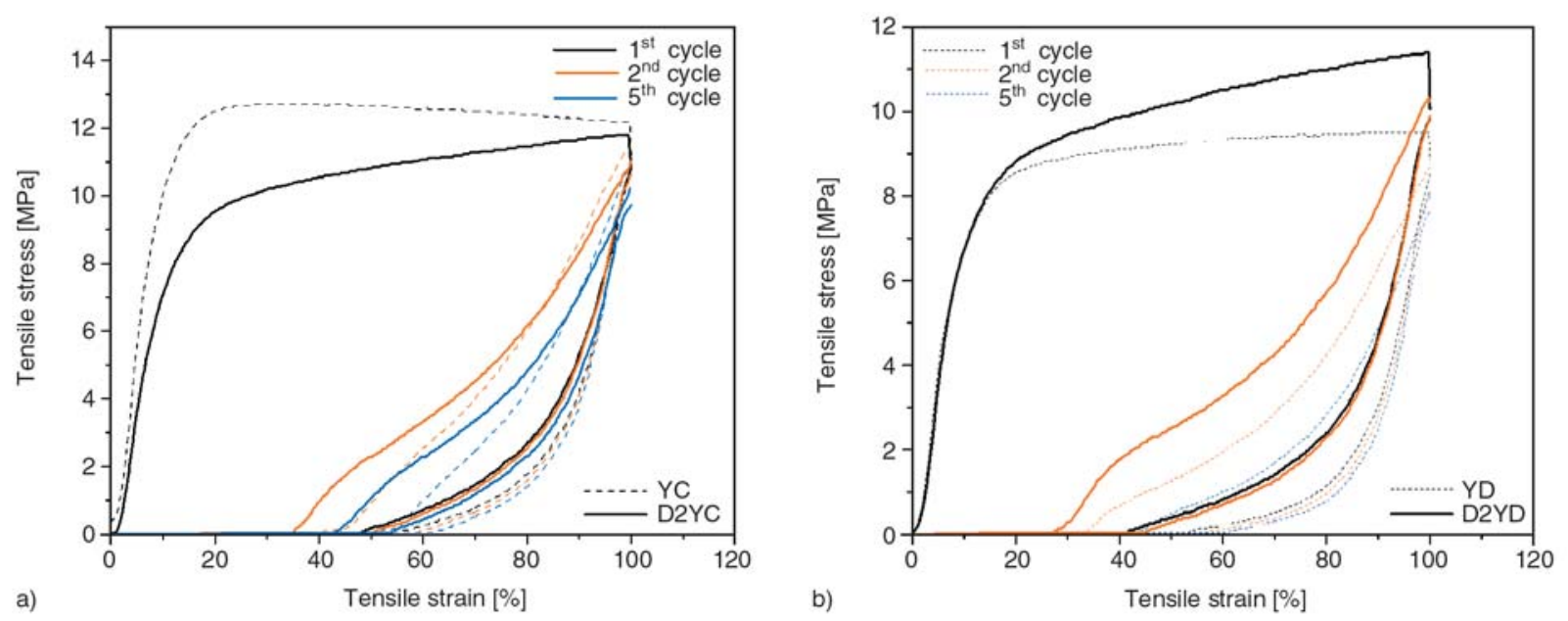

Figure 5. Stress-strain hysteresis loops during cyclic tension at constant strain of 100\% (a) 50/50 PP/EOC uncrosslinked and dynamically crosslinked blends (b) 50/50 PP/EPDM uncrosslinked and dynamically crosslinked blends

Table 6. Results of hysteresis test at constant strain of $100 \%$

\begin{tabular}{|c|c|c|c|c|c|c|}
\hline \multirow{2}{*}{$\begin{array}{c}\text { Compound } \\
\text { name }\end{array}$} & \multicolumn{3}{|c|}{ Residual strain [\%] } & \multicolumn{3}{c|}{ Max. stress [MPa] } \\
\cline { 2 - 7 } & $\mathbf{1}^{\text {st }} \mathbf{c y c l e}$ & $\mathbf{2}^{\text {nd }} \mathbf{c y c l e}$ & $\mathbf{5}^{\text {th }}$ cycle & $\mathbf{1}^{\text {st }}$ cycle & $\mathbf{2}^{\text {nd }}$ cycle & $\mathbf{5}^{\text {th }}$ cycle \\
\hline YC & 41.0 & 43.0 & 51.1 & 11.8 & 11.2 & 10.8 \\
\hline YD & 35.0 & 37.5 & 44.2 & 9.4 & 8.7 & 8.0 \\
\hline D2YC & 34.3 & 36.4 & 43.3 & 11.8 & 10.9 & 10.2 \\
\hline D2YD & 27.8 & 29.5 & 29.0 & 11.3 & 10.3 & 10.1 \\
\hline
\end{tabular}

characteristic feature of a thermoplastic material: an initial linear elastic behavior followed by gradual yielding [30]. Compared to uncrosslinked blends, TPVs exhibit steady strain hardening effect immediately after yielding. According to Soliman et al. [31] the deformation mechanism of PP/ EPDM TPVs (as shown in Figure 6) is the combination of matrix yielding and buckling of yielded PP matrix by the recovering tendency of crosslinked rubbery particles. During stretching, PP acts as glue between the crosslinked EPDM particles and part of the PP fractions undergo yielding in the direction perpendicular to the load. During recovery, the yielded PP fraction is partially pulled back by the recovering tendency of the crosslinked particles. During recoiling, the residual strain or permanent

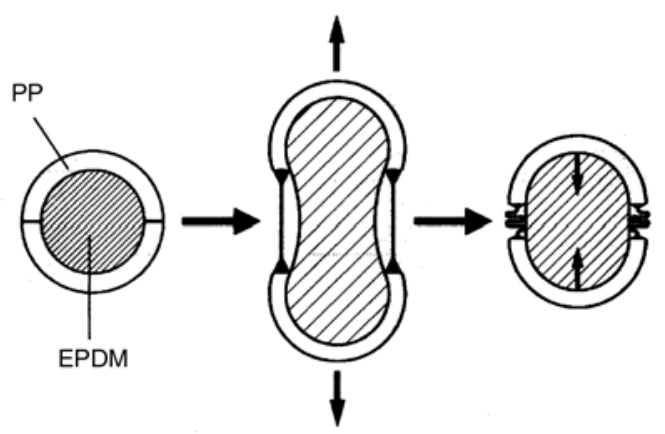

Figure 6. Deformation mechanism of TPVs suggested by Soliman et al. [31] set is observed due to matrix yielding. All the samples exhibit a decrease in the maximum stress level which can be explained by strain softening effect. It is clear from the Table 6 and Figure 5; significant softening is occurred in the first cycle followed by gradual softening effect with increase in number of cycles. A plausible mechanism for the observed changes could be due to disentanglement and slippage of polymer chains as a consequence of matrix yielding or shear banding. In both the cases, (PP/ EOC and PP/EPDM) the dynamically vulcanized blends decrease the setting behavior and lower the energy loss, a characteristics feature of elastomeric material. Furthermore, comparing the hysteresis behavior of two material classes, D2YC and $\mathrm{D} 2 \mathrm{YD}$, it is seen that latter exhibits less setting behavior in combination with lower energy loss. It may be due to the inherent physical crosslinks by higher chain entanglement density.

Samples have been subjected to stepwise increasing strain test (SIST) to understand the structural changes of the material as a function of cyclic fatigue straining. Figures $7 \mathrm{a}$ and $7 \mathrm{~b}$ demonstrate the results of the SIST of uncrosslinked and dynamically crosslinked blends subjected to straining at predetermined values of 20,50,100, 150 and $180 \%$ at a same speed of $500 \mathrm{~mm} / \mathrm{min}$. From the 

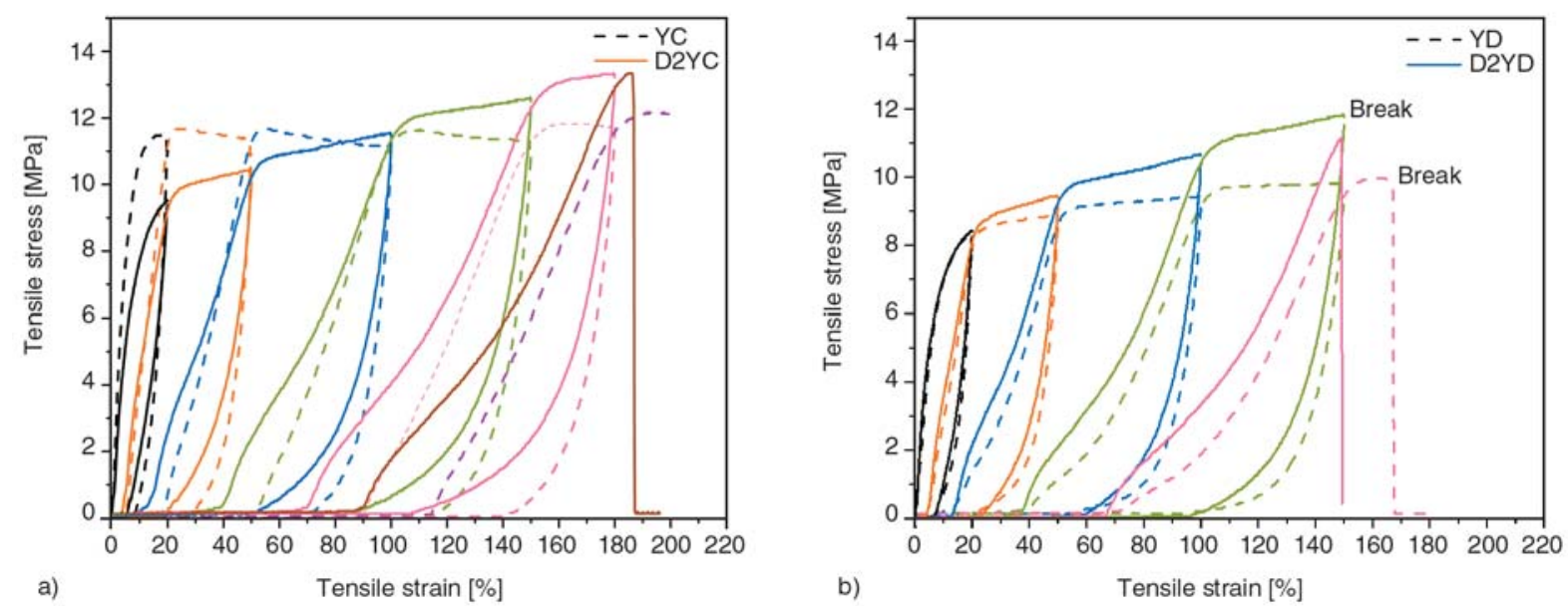

Figure 7. Stepwise hysteresis loops during cyclic tension (a) 50/50 PP/EOC uncrosslinked and dynamically crosslinked blends (b) 50/50 PP/EPDM uncrosslinked and dynamically crosslinked blends

Figures $7 \mathrm{a}$ and $7 \mathrm{~b}$, it is clear that the residual strain or irreversible strain is smaller in low strain region but becomes significantly higher at higher strain level. Therefore, the TPVs exhibit rubber like elastic deformation in the low strain region. But with increasing the strain level, elastic deformation is superimposed with irreversible plastic deformation. Although, PP/EPDM based uncrosslinked blend and dynamically blends exhibit lower setting tendency and energy loss than corresponding PP/EOC based blends but with poor fatigue resistance (failed before completing fourth cycle). The improved fatigue behavior of D2YC can be explained by the fact of better interfacial adhesion between the blend components.

\section{Conclusions}

The morphological, thermal and mechanical results are interpreted in terms of the balance between the crosslinking in the EOC and EPDM phases versus degradation in the PP phase. It is worth noting that, PP segments in the EPDM rubber might also undergo chain-scission and/or disproportionation reaction during dynamic vulcanization. So the obtained results are indeed the balance of the above mentioned reactions in the constituent polymers. The morphology of PP/EOC and PP/EPDM blends indicate a two phase morphology in which the rubber phase is dispersed in continuous PP matrix at lower rubber/plastic blend ratio and followed by phase inversion with increase in rubber/plastic blend ratio. The 50/50 composition of rubber/plastic shows co-continuous phase morphology. How- ever, after dynamic vulcanization all the samples exhibit a dispersed phase morphology in which crosslinked rubber particles are dispersed in continuous PP matrix. The dispersion characteristics of the dispersed crosslinked rubber phase are mainly influenced by the melt viscosity ratio, shear rate, curative dosage and the rubber content.

The crystallinity of the PP phase in TPVs is more or less comparable for both the systems employed. Therefore the stress-strain response of the PP/EOC and PP/EPDM dynamically crosslinked blends at identical composition is found to depend on the dispersion characteristics of the crosslinked rubber phase. Dynamically vulcanized blends having higher rubber/plastic ratio show thermoplastic elastomeric characteristics, whereas those having higher plastic/rubber ratio show poor mechanical properties due to degradation in the PP phase. When compared to the conventional PP/EPDM TPVs, PP/EOC TPVs show lower viscosity and elasticity in the melt state and better physicomechanical properties in the solid state. Hystersis measurements have been found to be a useful tool to evaluate the structural changes during dynamic deformation and fatigue analysis. Dynamically vulcanized 50/50 rubber/ plastic blend shows lower energy loss and better set properties. Although, PP/EPDM TPVs show lesser relaxation than corresponding PP/EOC TPVs but show poor fatigue characteristics.

In short, PP/EOC shows better mechanical, and thermal properties which may be due to better interfacial interaction and unique molecular microstructure of the EOC phase. In addition to lower cost, 
EOC are supplied in free pellets which allow for both batch and continuous production of TPVs. So, peroxide cured PP/EOC TPVs combine better processing characteristics with superior performance in the solid state. Hence, peroxide cured PP/EOC can be considered as a potential alternative to the conventional PP/EPDM TPVs.

\section{Acknowledgements}

The authors are grateful to the Council of Scientific and Industrial Research (CSIR), New Delhi, India for financial assistance.

\section{References}

[1] Paul D. R., Bucknall C. B.: Polymer blends. Wiley, New York (2000).

[2] Karger-Kocsis J.: Thermoplastic rubbers via dynamic vulcanization. in 'Polymer blends and alloys' (eds.: Shonaike G. O., Simon G. P.) Marcel Dekker, New York (1999).

[3] De S. K., Bhowmick A. K.: Thermoplastic elastomers from rubber plastic blends. Horwood, London (1990).

[4] Coran A Y., Patel R., Williams D.: Rubber-thermoplastic compositions. Part V. Selecting polymers for thermoplastic vulcanizates. Rubber Chemistry and Technology, 55, 116-136 (1982).

[5] Naskar K.: Thermoplastic elastomer based on PP/ EPDM blends by dynamic vulcanization - Review. Rubber Chemistry and Technology, 80, 504-510 (2007).

[6] Walton K. L.: Metallocene catalysed ethylene/alpha olefin copolymers used in thermoplastic elastomers. Rubber Chemistry and Technology, 77, 552-568 (2004).

[7] McNally T., McShane P., Nally G. M., Murphy W. R., Cook M., Miller A.: Rheology, phase morphology, mechanical, impact and thermal properties of polypropylene/metallocene catalysed ethylene 1octene copolymer belnds. Polymer, 43, 3785-3793 (2002).

DOI: $10.1016 / \mathrm{S} 0032-3861(02) 00170-2$

[8] Da Silva A. L. N., Rocha M. C. G., Coutinho F. M. B., Bretas R., Scuracchio C. J.: Rheological, mechanical, thermal, and morphological properties of polypropylene/ethylene-octene copolymer blends. Journal of Applied Polymer Science, 75, 692-704 (2000).

DOI: $10.1002 /($ SICI $) 1097-4628(20000131) 75: 5<692$ $\because$ AID-APP12>3.0.CO;2-Y

[9] van Duin M.: Recent developments for EPDM-based thermoplastic vulcanisates. Macromolecular Symposia, 233, 11-16 (2006).

DOI: $\underline{10.1002 / \text { masy.200690006 }}$
[10] Dluzneski P. R.: Peroxide vulcanization of elastomers. Rubber Chemistry and Technology, 74, 451-490 (2001).

[11] Naskar K., Noordermeer J. W. M.: Dynamically vulcanized PP/EPDM blends: Effects of different types of peroxide on the properties. Rubber Chemistry and Technology, 76, 1001-1018 (2003).

[12] Naskar K., Noordermeer J. W. M.: Dynamically vulcanized PP/EPDM blends: Effects of multifunctional peroxides as crosslinking agents. Rubber Chemistry and Technology, 77, 955-971 (2004).

[13] Naskar K., Gohs U., Wagenknecht U., Heinrich G.: PP-EPDM thermoplastic vulcanisates (TPVs) by electron induced reactive processing. Express Polymer Letter, 3, 677-683 (2009).

DOI: 10.3144/expresspolymlett.2009.85

[14] Basuli U., Chaki T. K., Naskar K.: Influence of Engage ${ }^{\circledR}$ copolymer type on the properties of engage/ silicone rubber-based thermoplastic dynamic vulcanizates. Express Polymer Letters, 2, 846-854 (2008). DOI: $10.3144 /$ expresspolymlett.2008.99

[15] Naskar K., Chatterjee K.: Development of thermoplastic elastomers based on maleated ethylene propylene rubber and polypropylene by dynamic vulcanization. Express Polymer Letters, 1, 527-534 (2007). DOI: $10.3144 /$ expresspolymlett.2007.75

[16] Lai S-M., Chin F-C., and Chiu T-Y.: Fracture behaviors of $\mathrm{PP} / \mathrm{mPE}$ thermoplastic vulcanizate via peroxide crosslinking. European Polymer Journal, 41, 30313041 (2005).

DOI: 10.1016/j.eurpolymj.2005.06.003

[17] Babu R. R., Singha N. K., Naskar K.: Studies on the influence of structurally different peroxides in polypropylene/ethylene alpha olefin thermoplastic vulcanizates (TPVs). Express Polymer Letters, 2, 226-236 (2008).

DOI: $10.3144 /$ expresspolymlett.2008.27

[18] Babu R. R., Singha N. K., Naskar K.: Dynamically vulcanized blends of polypropylene and ethylene octene copolymer: Influence of various coagents on mechanical and morphological characteristics. Journal of Applied Polymer Science, 113, 3207-3221 (2009). DOI: 10.1002/app.30000

[19] Babu R. R., Singha N. K., Naskar K.: Melt viscoelastic properties of peroxide cured polypropylene-ethylene octene copolymer thermoplastic vulcanizates. Polymer Engineering and Science, 50, 455-467 (2010). DOI: $10.1002 /$ pen.21553

[20] Babu R. R., Singha N. K., Naskar K.: Effects of mixing sequence on peroxide cured polypropylene (PP)/ ethylene octene copolymer (EOC) thermoplastic vulcanizates (TPVs). Part I. Morphological, mechanical and thermal properties Journal of Polymer Research, in press (2010). DOI: $10.1007 / \mathrm{s} 10965-009-9354-\mathrm{Z}$ 
[21] Flory P. J., Rehner J. J.: Statistical mechanics of crosslinked polymer networks. II. Swelling. Journal of Chemical Physics, 1, 521-526 (1943). DOI: $10.1063 / 1.1723792$

[22] Varghese S., Alex S., Kuriakose B.: Natural rubberisotactic polypropylene thermoplastic blends. Journal of Applied Polymer Science, 92, 2063-2068 (2004). DOI: $10.1002 / a p p .20077$

[23] Harrats S., Thomas S., Groeninckx G.: Micro and nano structured multiphase polymer blend systems: Phase morphology and interface. CRC Press, Boca Raton (2006).

[24] Paul D. R., Newman S.: Polyolefin blends: Rheology, melt mixing, and applications in polymer blends. Academic Press, New York (1978).

[25] D’Orazio L., Mancarella C., Martuscelli E., Polato F.: Polypropylene/ethylene-co-propylene blends: Influence of molecular structure and composition of EPR on melt rheology, morphology and impact properties of injection-moulded samples. Polymer, 32, 11861194 (1991).

DOI: $10.1016 / 0032-3861(91) 90220-\mathrm{D}$

[26] Prut E. V., Erina N. A., Karger-Kocsis J., Medintseva T. I.: Effects of blend composition and dynamic vulcanization on the morphology and dynamic viscoelastic properties of PP/EPDM blends. Journal of Applied Polymer Science, 109, 1212-1220 (2008).

DOI: $10.1002 /$ app. 28158
[27] Da Silva A. L. N., Tavares M. I. B., Politano D. P., Coutinho F. M. B., Rocha M. C. G.: Journal of Applied Polymer Science, 66, 2005-2014 (1997). DOI: $10.1002 /($ SICI $) 1097-4628(19971205) 66: 10$ $\leq 2005::$ AID-APP17>3.0.CO;2-2

[28] Bielinski D. M., Ślusaraki L., Wlochowicz A., Ślusarczyk C., Douillard A.: Some aspect of isotactic polypropylene crystallization in an ethylene-propylene-diene rubber matrix. Polymer International, 44, 161-173 (1997).

DOI: $10.1002 /($ SICI $) 1097-0126(199710) 44: 2<161$ $\because$ AID-PI837>3.0.CO;2-T

[29] Martuscelli E., Silvestre C., Abat G.: Morphology, crystallization and melting behavior of films of isotactic polypropylene blended with ethylene-propylene copolymers and polyisobutylene. Polymer, 23, 229237 (1982).

DOI: $10.1016 / 0032-3861(82) 90306-8$

[30] Boyce M. C., Yeh O., Socrate S., Kear K., Shaw K.: Micromechanics of cyclic softening in thermoplastic vulcanizates. Journal of Mechanics and Physics of Solids, 49, 1343-1360 (2001).

DOI: $\underline{10.1016 / \mathrm{S} 0022-5096(00) 00077-6}$

[31] Soliman M., Dijk M. V., Es M. V., Shulmeister V.: Deformation mechanism of thermoplastic vulcanisates investigated by combined FTIR and stress-strain measurements. in 'Proceedings of ANTEC '99, New York, USA' vol 2, 1947-1954 (1999). 